\title{
Recorrências na abordagem de velhices centenárias em matérias de perfil
}

\section{Recurrences in the approach of centenarians in the media}

Cíntia Liesenberg ${ }^{1}$ em Comunicação Social, com habilitação em Relações Públicas, pela Pontifícia Universidade Católica de Campinas (PUC-Campinas) (1991). Docente do Centro de Linguagem e Comunicação da Pontifícia Universidade Católica de Campinas desde 2005. E-mail: acintialie@gmail.com. 


\section{Resumo}

O artigo baseia-se em achados da pesquisa de doutorado que buscou problematizar discursos e representações sociais da velhice em circulação nas mídias. Foca-se na análise de recorrências em torno de velhices centenárias, levantadas em matérias do gênero perfil, compartilhadas pela página do Portal do Envelhecimento no Facebook. Tem como apoio as Ciências da Linguagem e a Análise de Discurso francesa, entre outros fundamentos. Como resultado principal, encontra uma cena enunciativa que toma essas velhices como locus do saber sobre o segredo da longevidade, mas que, no entanto, anula sua voz.

\section{Palavras-chave}

Velhice centenária, ciências da linguagem, análise do discurso, crítica de mídia.

\section{Abstract}

This article is based on a doctoral dissertation that sought to analyze discourses and social representations of old age in circulation at the media. It focuses on recurrences related to centenarians found in newspaper articles of the profile genre shared at the webpage Portal do Envelhecimento, hosted on Facebook. This study is grounded on Language Sciences and the theoretical framework of French Discourse Analysis, among others. The results show an enunciative scene that considers centenarians as the locus of knowledge wherein lies the "secret of longevity", which instead ends up nullifying their voice.

\section{Keywords}

Centenarians, language sciences, discourse analysis, media criticism. 


\section{Recorrências na abordagem de velhices centenárias em matérias de perfil}

O artigo pauta-se pelos achados da pesquisa de doutorado (LIESENBERG, 2019) que buscou problematizar representações sociais e discursos em circulação nas mídias pelo tema da velhice e do envelhecimento.

A partir dela, analisam-se perfis de idosos, compartilhados pela página do Facebook, Portal do Envelhecimento (2011), que é referência na promoção da temática. Como fundamentos que sustentam a análise, apoiamo-nos nas Ciências da Linguagem, que entendem os processos midiáticos na tessitura de redes simbólicas (SOARES, 2009, p. 109), que nos situam como seres no mundo. Entre os demais aportes do trabalho, recorremos ainda aos estudos de Deleuze e Guattari (2011a, 2011b), que tomam a linguagem como transmissão de palavras de ordem, as quais dispõem coordenadas para a ação dos sujeitos.

Nesse terreno, a metodologia sustentou-se em princípios da Análise de Discurso de linha francesa, que abarca o discurso como prática social que confere sentidos à experiência humana (MAINGUENEAU, 1989, p. 11). Ela foi dividida em dois momentos principais: o primeiro, de teor exploratório, resultou em um mapeamento de ocorrências e forneceu as bases para o recorte final do corpus e posterior análise, desenvolvida no segundo momento.

O corpus final foi composto por quatro recortes entre as matérias encontradas: velhices anônimas, velhices públicas, velhices LGBTI (lésbicas, gays, bissexuais, transgêneros e intersex) e velhices centenárias.

Para este artigo, tratamos mais especificamente das recorrências principais encontradas em torno desse último recorte. Trazemos também um panorama sobre a velhice e o envelhecimento populacional, apresentamos os fundamentos que nos sustentam, bem como as fases da pesquisa que levaram ao recorte do corpus e eixo desta análise.

Como resultado, observa-se aí, como primeiro elemento redundante, a apresentação dessas velhices como locus detentor do segredo para a longevidade. Por outro lado, vemos a anulação de voz dessas velhices, uma vez que sua palavra é sempre validade ou mesmo refutada por outro agente da enunciação. 
Por outro lado, muitas vezes, esses outros agentes que compõem a narrativa, ainda que detentores de um lugar de fala privilegiado na cena enunciativa, têm também sua voz interdita, isso porque operam apenas como elemento balizador da fala das centenárias. Assim, temos a anulação sucessiva de vozes que poderiam, de outra forma, nos levar a compreender e discutir melhor o universo da velhice e do envelhecimento em nossos dias.

Nesse sentido, considerando o recorte aqui analisado e a recorrência da ideia da velhice centenária como locus detentor do segredo para a longevidade, ainda que as matérias nos apresentem idiossincrasias de nossos velhos e aspectos em que vemos materializada a importância simbólica das particularidades na atribuição de sentido para a vida dos sujeitos, temos uma cobertura midiática superficial e simplista, pautada na mesmice de um argumento que pouco nos dá a conhecer sobre a realidade de que trata.

Dessa forma, entendemos que a abordagem pelas mídias dos discursos e representações sociais da velhice e do envelhecimento se faz importante objeto de análise e crítica, uma vez que tratamos de tema nevrálgico que pede abordagens mais amplas diante de sua crescente relevância social, como diversos estudos demonstram (ILC, 2015).

\section{Um panorama sobre a velhice e o envelhecimento na atualidade}

As questões sobre velhice e envelhecimento são preocupação desde a antiguidade. De um lado, a velhice era apreendida como meta positiva, lugar da sabedoria e do desapego, mas, de outro, era vista também como um valor limitado, quando associada aos penares do declínio orgânico (FOUCAULT, 2010). Ao longo do tempo, esse último aspecto se sobressai, pelo olhar da velhice sob os domínios da medicina (SILVA, 2008).

Por outro lado, mais recentemente, a velhice passa a ser entendida também como momento de maior plenitude e liberdade para os sujeitos, fase propícia para a retomada de projetos (DEBERT, 2012; GOLDENBERG, 2015), período não apenas de perdas, mas também de ganhos, circunscrita por novos discursos em ascensão, como aquele do envelhecimento ativo (ILC, 2015). 
Em termos demográficos, deparamo-nos com o aumento da expectativa de vida e crescimento vertiginoso da população idosa global (ILC, 2015). Até 2022, o mundo deve alcançar a marca de um bilhão de pessoas acima dos 60 anos (BRASIL, 2012). Para 2050, prevê-se que o número de indivíduos nessa faixa etária ultrapasse o número de crianças abaixo dos 15 anos (BRASIL, 2012; ILC, 2015). Estima-se que, então, entre $21 \%$ e $22 \%$ da população mundial seja constituída por pessoas acima dos 60 anos, o que corresponde a dois bilhões de indivíduos (BRASIL, 2012; ILC, 2015). Em diversos países desenvolvidos, mas também "na maior parte da América Latina e grandes partes da Ásia" as projeções vão a $30 \%$ da população (ILC, 2015, p. 14).

De forma geral, grupos populacionais de maior idade estão crescendo mais rapidamente (ILC, 2015, p. 15). No Brasil, segundo dados do IBGE, em 2016, a população de idosos com 80 anos ou mais contabilizava quase 3,5 milhões de pessoas (3.458.279). Nas projeções do mesmo instituto, em 2060, o número de sujeitos nessa faixa etária, no país, pode ultrapassar a marca dos 19 milhões (LISBOA, 2016).

Quanto aos centenários, população objeto deste artigo, embora seja ainda uma parcela pequena da população, considera-se que seu número também aumente: "de cerca de 300.000 em todo o mundo em 2011 para 3,2 milhões até 2050" (ILC, 2015, p. 15)².

A exemplo do fenômeno mundial, as mudanças na pirâmide etária brasileira decorrem principalmente da redução dos índices de mortalidade, inclusive a infantil, combinada à alta taxa de natalidade nas duas décadas após a Segunda Guerra Mundial (baby boom), como também, da redução dos índices de natalidade, incentivada por políticas de planejamento familiar (ILC, 2015; SIMÕES, 2016).

Compondo o cenário, tanto a expectativa de vida quanto a expectativa de vida saudável aumentaram. No entanto, esta última, de forma mais lenta 
(ILC, 2015, p. 16). Tais alterações na redistribuição das proporções etárias, com aumento do número de pessoas longevas vivendo em diferentes condições, tornam relevante que se adote um novo olhar para a sociedade (CAMARANO; PASINATO, 2004; FALEIROS, 2016; GIACOMIN, 2016; SIMÕES, 2016; entre outros).

Nesse contexto, nosso interesse volta-se para a forma como a temática vem sendo exposta pelas mídias, considerando a relevância social da velhice em nossos dias e o lugar privilegiado que as mídias ocupam na circulação discursiva, entendendo que nossa apreensão do mundo se pauta por discursos que a sustentam.

\section{Elementos teóricos e metodológicos que nos orientaram}

Para o estudo que aqui apresentamos, situamos o trabalho no terreno das Ciências da Linguagem, como espaço de conhecimento que abarca aquilo que emerge do âmbito simbólico (GOMES, 2000).

Assim, para além das concepções instrumentais centradas no esquema básico emissor-mensagem-receptor (FREITAS, 1992, p. 12), temos aí um terreno para se pensar a Comunicação como campo de interação entre sujeitos. Estes passam a ser vistos como seres sociais que habitam a ordem simbólica, são constituídos pela linguagem e pelos discursos que a materializam.

Ao entendermos o âmbito simbólico como elemento fundante de toda e qualquer sociedade e elaboração humana, instituinte dos processos de apreensão do mundo, temos um terreno vasto para estudos e problematizações dos sentidos, representações e discursos colocados em circulação nas mídias em torno de nosso objeto, bem como das certezas que o recortam. Ainda mais ao se considerar que, de nossa apreensão de mundo, mediada pela linguagem, sempre sobra um resto passível de reinscrição - resto que se apresenta para nós nos vestígios de outras possíveis tomadas ou como face não abordada (GOMES, 2000).

É dessa forma que importa também pensar na linguagem em termos de apresentação de palavras de ordem e na subjetividade, em termos de subjetivação ou sujeição em atenção ou não ao caráter disciplinar que essas palavras imprimem, na medida em que são enunciadas (DELEUZE; GUATTARI, 2011a, 2011b). Tais 
palavras podem então ser entendidas como intervenção da expressão nos corpos, uma vez que, na expressão dos enunciados, "não representamos, não referimos, intervimos de algum modo" (DELEUZE; GUATTARI, 2011b, p. 29).

Nesse terreno, as palavras de ordem inscrevem-se como elementos relativos à nossa forma de se postar no mundo, uma vez que estão vinculadas, de maneira implícita, "a todos os atos que estão ligados aos enunciados por uma "obrigação social" (DELEUZE; GUATTARI, 2011b, p. 17).

Tal relação entre palavra/enunciado e pressupostos implícitos é de redundância e permite associar o conceito de palavra de ordem de Deleuze e Guattari àquele dos dispositivos disciplinares de Foucault (2010), uma vez que ambos implicam a disposição de coordenadas em relação a tomadas de posição e obrigações sociais que devem ser seguidas pelos sujeitos, a partir de uma visão de mundo que as condicionam (GOMES, 2003).

Tal questão é extremamente relevante para este trabalho, pois tange a construção de direcionamentos para as ações humanas, sendo as mídias (nosso aparato no estudo dos discursos sobre a velhice) elemento que assume papel ordenador, "pelo fato de nos dizerem o que é 'necessário' pensar, remeter, esperar, etc." (DELEUZE; GUATTARI, 2011b, p. 17)³.

Nesse processo, a informação é considerada como um vetor para as palavras de ordem, cujo papel disciplinar é reforçado na redundância em que se apresentam, aspecto que direciona nosso olhar para o estudo da velhice e que é evidenciado neste artigo na abordagem das matérias sobre velhices centenárias. Por outro lado, entendemos que tal processo também apreende a possibilidade de ruptura com o estabelecido, sendo terreno dos acontecimentos e das experiências, como realidade sempre passível de novos agenciamentos, novas ordenações e subjetivações.

O exposto nos auxilia a pensar em nosso objeto em circulação nas mídias, na busca pela conformação que a linguagem confere à temática, nesse terreno de ampla visibilidade. 
Na tentativa de estruturação de uma metodologia para a conformação e análise do corpus, recorremos a princípios da Análise de Discurso (AD) de linha francesa que entende os discursos como eventos verbais no mundo (MAINGUENEAU, 1989; ORLANDI, 2013), e correlaciona diretamente ao terreno das Ciências da Linguagem. Destaca-se, daí, a própria noção de constituição imaginária da realidade, uma vez que esta só nos é acessível quando mediada pela linguagem e pelos recortes simbólicos que permitem a nomeação e a atribuição de significados às coisas do mundo.

A realidade é compreendida, assim, como terreno que se constitui no esquecimento de nossa imersão nessa rede imaginária que acionamos no momento da enunciação e, também, no esquecimento de nossa constituição pelos discursos que nos antecedem (ORLANDI, 2013; PÊCHEUX, 1997). Consiste aí a eficácia da ordem simbólica: no apagamento do real do acesso ao mundo apenas por sua inscrição como construto, a partir dos discursos em que nos engajamos como nossos, mas que, anteriores a nós, vêm sempre de outro lugar.

\section{Fases da pesquisa: mapeamento de ocorrências e o encontro com as velhices centenárias}

Na operacionalização desses princípios metodológicos, o percurso foi dividido em duas etapas: a primeira constituída por pesquisa exploratória ${ }^{4}$ que forneceu maior conhecimento de nosso objeto e as bases para o recorte do corpus; e a segunda, mais especificamente voltada para o desenvolvimento da análise.

Inicialmente, optou-se pela realização da pesquisa a partir de um espaço que permitisse reunir publicações variadas em circulação nas mídias sobre a temática. Daí a escolha do ambiente digital da world wide web e da plataforma de mídias digitais Facebook.

Tal opção é justificada em função do fortalecimento de uma cultura em que os sujeitos são incentivados a procurar novas informações e fazer conexões em

"Pesquisas exploratórias são desenvolvidas com o objetivo de proporcionar visão geral, de tipo aproximativo, acerca de determinado fato" (GIL, 2008, p. 27). São desenvolvidas, muitas vezes, como a primeira etapa de uma pesquisa mais ampla, quando o tema em estudo é bastante genérico, exemplo de nosso caso (GIL, 2008). 
meio a conteúdos de mídia dispersos (JENKINS, 2009, p. 29), sendo o espaço da web um locus privilegiado para tal, por permitir acesso a tais conteúdos a partir de pontos localizados, que remetem a outros, em uma organização hipertextual ${ }^{5}$.

Diante da vastidão da web, destacam-se para nós as comunidades do Facebook, cujas páginas são criadas a partir de interesses comuns de seus produtores e integrantes (KIRKPATRICK, 2011) e situadas como espaço potencial de convergência midiática. Esse é o caso das fan pages, ou comunidades de fãs, voltadas para o tema da velhice e do envelhecimento. Nelas, são compartilhados materiais sobre o assunto a partir das fontes mais variadas, de diferentes suportes e formatos genéricos.

Daí a escolha dessa plataforma como porta para um universo mais amplo de outros sítios ou publicações midiáticas que veiculam e compartilham informações sobre a temática, considerando ainda seu lugar de destaque entre as redes em âmbito mundial, como também no Brasil ${ }^{6}$.

Para a pesquisa exploratória, a escolha das páginas do Facebook utilizadas decorreu de buscas por palavras-chave, como velhice, envelhecimento e geriatria, como também pelo número de curtidas na época dos levantamentos. Considerou-se ainda o conteúdo das postagens ser, em maior parte, explicitamente relacionado à velhice ou envelhecimento, ao que se somou ao caráter exploratório, um viés intencional. Daí foram selecionadas as páginas Velhices (2013), Portal do Envelhecimento (2011) e Geriatria e Gerontologia (2013)7. Além dessas, foi também incluída a página Instituto de Língua e Cultura Brasileira - ILC-Brasil (2015), pelo lugar de referência ocupado pela organização e atuação em nível global e regional ${ }^{8}$.

Define-se hipertexto como "uma forma não-linear de apresentar e consultar informações. Um hipertexto vincula as informações contidas em seus documentos [...] criando uma rede de associações complexas através de hyperlinks ou, mais simplesmente links" (LÉVY, 1999, p. 254). com pesquisa da ComScore (BANKS; VP AMÉRICA LATINA; DIRETOR BRASIL, 2014) - empresa de atuação global de medição de audiência digital -, como também, a ratificação de tal posicionamento pelo relatório divulgado pelo Facebook, em abril de 2018, segundo Agência Brasil (VALENTE, 2018). 
O levantamento nas páginas selecionadas permitiu o encontro de quantidade e variedade de material vasto. Em termos quantitativos, foram levantadas 634 publicações num período de busca compreendido entre 5 de novembro de 2016 a 4 de janeiro de 2017, com ligeira variação entre as fontes.

Os dados colhidos ofereceram rico panorama sobre o tema e possibilitaram a elaboração de um mapeamento amplo das postagens realizadas. A partir de características comuns das postagens ou de destaque quanto ao tipo de conteúdo ou formato, os materiais foram aglutinados em 15 tipologias, de onde foi feita a escolha das matérias do gênero perfil para a composição do corpus final do trabalho.

Tal corpus compreende as matérias em que ocorre a "descrição (interior ou exterior) de um personagem" (FERRARI; SODRÉ, 1986, p. 125). De maneira mais específica, o perfil significa também o "enfoque na pessoa - seja uma celebridade ou um tipo popular" focalizado como protagonista de sua história de vida (FERRARI; SODRÉ, 1986, p. 126).

Incluem-se aí entrevistas com personalidades, "com informações biográficas, com as ideias, opiniões do entrevistado, descrevendo seu modo de falar, suas roupas e gestos" (MELO, et al., 1998), associadas a algum fato da atualidade que motiva a matéria.

A escolha pelo discurso jornalístico se dá em função de seu posicionamento como organizador do espaço social e que se posta em nome do interesse público (GOMES, 2000). Ocupa assim o lugar do mediador autorizado a narrar e informar os acontecimentos do mundo e a apresentar uma realidade à comunidade de coenunciadores aos quais se direcionam os seus discursos.

Do ponto de vista do discurso informativo, inerente ao jornalismo, Patrick Charaudeau afirma que se deposita uma posição forte de autoridade no sujeito que ocupa o papel de locutor desse discurso, por ser "detentor de um saber que o outro não possui" (CHARAUDEAU, 2012, p. 63), o que lhe insere também em um lugar de poder.

Esse poder, no entanto, assenta-se nos elementos referenciais colocados em evidência pelo discurso. O efeito de referencialidade aí erigido valida a cena 
enunciativa construída em torno do discurso informativo que circula nas mídias e no qual se ancora o discurso jornalístico.

Daí a escolha das matérias do gênero perfil para composição de nosso corpus. Estas, além de permitirem pensar as representações sociais dos idosos a partir de uma posição que os situam como elemento central da enunciação, colocam-nos diante de sujeitos concretos, elementos privilegiados de remissão ao real. São exemplos de vida referenciais que contribuem para o efeito de apagamento da mediação humana na apreensão da realidade em que nos inserimos e, assim, contribuem também para reforço da eficácia simbólica dos discursos proferidos (GOMES, 2000).

Para o recorte final do corpus, optamos pelo foco nas publicações da página do Portal do Envelhecimento, em função da variedade de suas publicações e fontes ${ }^{9}$, e por sua posição de referência e destaque no mapeamento de ocorrências.

Compõem o corpus as matérias encontradas durante a pesquisa exploratória, complementadas com outras compartilhadas entre 2 de fevereiro e 3 de outubro de 2018, num total de 54 publicações.

Estas foram divididas em quatro cenas principais, bastante destacadas: velhices anônimas, velhices públicas, velhices LGBTI e velhices centenárias, sendo essas últimas nosso objeto de análise neste artigo.

\section{Velhices centenárias: o segredo da longevidade e a destituição de voz de sujeitos do discurso}

Das matérias que compuseram o corpus final, 10 delas constituíram o recorte das velhices centenárias. Como aspecto recorrente, temos a apresentação dessas velhices como detentoras do saber sobre o segredo da longevidade. Em números concretos, com maior ou menor ênfase, 7 entre as 10 matérias se estruturaram com base nesse argumento. 
As duas primeiras tratam de Ema Morano, falecida com 117 anos, em abril de 2017, considerada na época a mulher mais velha do mundo. Uma delas (RYAN, 2016) traz breve perfil da senhora e é pautada pelo segredo da longevidade, revelado logo no título: "ser solteira e comer ovos". A outra (COMO..., 2016) é motivada pelo aniversário de 117 anos da senhora, mas ancora-se sobre o mote da revelação de sua dieta.

A terceira, sobre Ângela Bortolini (101), do Diário de Canoas/RS (SOUZA, 2018) apresenta a questão no decorrer da matéria. Somam-se a elas as matérias sobre Leah Bandeira Sacchi (106), publicada pelo blog VivaBem (TERRIE, 2018), do Uol; e aquela publicada pelo G1 (PIMENTEL, 2018) sobre Maria Marques de Figueiredo (Dona Lica), de 105 anos.

Além dessas, temos ainda duas outras matérias de veículos portugueses: uma publicada pela revista online Delas (A MULHER..., 2018), sobre Grace Jones, que anuncia que a senhora chegou à idade de 112 anos tomando um copo de whisky por dia; e outra, do Correio da Manhã, de Lisboa (MULHER..., 2018), sobre Brenda Osborne (105), cujo segredo, mencionado no título, revela-se durante a matéria: "Colocar a saúde em primeiro lugar, trabalhar muito e evitar os homens".

Todas essas giram em torno de hábitos alimentares ou de algum comportamento dos sujeitos centenários, como, por exemplo: tomar uma "pinguinha para limpar a garganta" e "uma cerveja antes do almoço" e "leite com conhaque antes de dormir" ou "manter a tranquilidade" e "não ter medo de nada".

As relações sociais e as atividades de rotina são, por vezes, também mencionadas:

Caminha diariamente, tem um diário onde registra suas atividades, sempre toma uma cervejinha antes do almoço, é cheia de amigos. Será essa a fórmula da longevidade? A animada senhora dá sua receita para se tornar uma centenária. (TERRIE, 2018)

As campeãs nas recomendações, juntamente com a alimentação, são as bebidas alcoólicas, na afirmação que são consumidas moderadamente, mas como hábito diário e, por vezes, validadas na enunciação pela fala de autoridade do saber médico: 
"Comecei a tomar um copo à noite quando fiz 50 anos, por isso tenho-o tomado todas as noites, nos últimos 60 anos, e certamente não faço tenções de parar agora. $O$ meu médico disse 'continue com o whisky Grace, faz-Ihe bem ao coração', disse, citada pelo jornal Daily Mail. (A MULHER..., 2018)

Todos os dias antes do almoço, eu tomo uma pinguinha para limpar a garganta e uma cerveja. Quando não tem, bebo vinho. Meu cardiologista diz que uma taça de vinho por dia fortalece o meu coração. (TERRIE, 2018)

Se, particularmente, os "segredos" revelados são tidos como signos que remetem a particularidades, gosto específico e presença no mundo de determinado sujeito, nas recorrências das matérias que giram prioritariamente em torno desse eixo da enunciação, vemos um discurso, em parte, mudo. Uma narrativa que, valorizando particularismos, toma a velhice centenária apenas como locus detentor de um segredo de vida extensivo à humanidade, tão mais valorado quanto mais exótico ou banal, como se o resultado de um percurso de vida tão longo, que inclui as condições do meio, época, além de um posicionamento individual, fosse apenas consequência daquilo que se expressa naquelas poucas linhas, naqueles hábitos.

O interesse efetivo pelo sujeito, por sua trajetória e presença no mundo tornam-se menores diante da receita para uma vida longa, traduzida, em geral, por atos corriqueiros, simples, e, por vezes, excêntricos, inscritos no ditame de uma vida a ser levada com bom humor e de forma leve.

Os mesmos adjetivos agregam-se então à figura ou representação do sujeito centenário, apresentado mais por tais particularidades do que por outros aspectos que o caracterizam ou que poderiam ser trabalhados, como algumas brechas deixam entrever.

Por outro lado, em suas excentricidades, o discurso desses velhos tão longevos conflita, muitas vezes, com os discursos em nome da qualidade de vida na velhice, da boa alimentação e outras palavras de ordem que se professam em nossos tempos. Ou seja, suas respostas inusitadas e a tentativa por vezes de domesticá-las tornam-se relevantes, apontando para uma cena que se apoia na representação da velhice avançada como guardiã dos segredos para uma vida longeva, mas que não cumpre muito com protocolos regulamentares e palavras de ordem sedimentadas como corretas. 
Os segredos desviantes são então resolvidos com a fala dos especialistas, seja na palavra médica ou na voz do veículo de imprensa. Estes retornam à enunciação a visada entendida como conduta correta, como os trechos das matérias sobre Emma Morano ilustram:

A longevidade de Emma, segundo ela, se deve em parte à genética - sua mãe viveu até os 91 anos e várias de suas irmãs chegaram ao centenário e, em outra, a uma dieta incomum que inclui ingerir três ovos (dois crus) todos os dias por mais de 90 anos. [...]

Isso vai contra todos os conselhos sobre vida saudável, afirma Carlo Bava, seu médico há 27 anos [...]. À agência AFP, ele disse que Emma sempre comeu poucos vegetais, muito poucas frutas. [...] Apesar disso, ele conta, Emma parece ser "eterna". (COMO..., 2016)

Mas antes que você vá ao mercado comprar três dúzias de ovos, vale lembrar que Emma também revelou ao The New York Times em 2015 que ser independente contribuiu muito para a sua longevidade [...]

Então, para todas as mulheres que queiram colocar em prática os ensinamentos da mulher mais velha do mundo, é importante ressaltar que os ovos devem ser consumidos com moderação e/ou de acordo com as orientações do seu médico. Os homens, por outro lado, não sabemos ao certo [...]. (RYAN, 2016)

Assim, quanto ao valor do lugar de fala das velhices centenárias, observase a necessidade de sua validação, o que se faz também por meio de familiares que operam na narrativa como agentes legitimadores de suas idiossincrasias e posicionamentos, muitas vezes assumindo sua voz, ou seja, falando em seu lugar. É o que os trechos ilustram:

De acordo com ela, [Valdênia Figueiredo] o segredo da longevidade da mãe é manter a tranquilidade e não ter medo de nada. "Com ela tudo pode. Até misturar manga com leite. Não tem problema nenhum", contou Valdênia. [...] Lica também não dispensa uma taça de vinho de vez em quando. "Até uma cervejinha ela toma. Come de tudo. Sempre teve uma vida tranquila. Acho que o segredo é esse", falou Valdênia. (PIMENTEL, 2018) 
"A minha tia não me surpreende, sempre foi muito independente. Ela acabou de se mudar para o lar no ano passado e faz muitas piadas ao dizer que o segredo para uma vida longa é evitar homens, porque eles não valem a pena", confessa Marie Pollard, sobrinha-neta de Brenda. (MULHER..., 2018)

Temos então uma cenografia paradoxal: estrutura-se uma narrativa que interpela o coenunciador pelo recurso à revelação de um segredo que the pode ser útil, ao mesmo tempo em que, na sequência, refuta o valor daquilo que é revelado ou a voz do sujeito detentor do saber a ser compartilhado.

As palavras dessas velhices centenárias, ouvidas como locus onisciente dos caminhos para a longevidade são, dessa forma, anuladas em nome de um discurso científico ou de um suposto saber que a contesta e enquadra, ou ainda, é terceirizada pelo dizer de um outro sujeito do discurso que toma efetivamente sua voz.

Por outro lado, em brechas do discurso de algumas dessas matérias e naquelas em que as velhices centenárias nos são apresentadas sobre outros moldes, vemos a exposição de situações relevantes que as envolvem, seja na exposição de uma rede social de amparo, a qual permite uma vida comunitária a Leah Bandeira Sacchi (106) (TERRIE, 2018), ou na exposição de temas polêmicos, como o posicionamento de David Goodall que, aos 104 anos, reivindica o direito de morte assistida (SAMORA, 2018); ou a vida ativa e socialmente engajada de Kirk Douglas, apresentada em razão de homenagem ao seu centenário (TORRES, 2016), por exemplo.

Essas outras visadas reforçam ainda mais nosso olhar para a destituição simbólica que ocorre nas matérias em torno das velhices centenárias, quando são apresentadas recorrentemente como locus do saber sobre a longevidade.

Quando pensamos nos discursos como espaços pelos quais se estabelece aquilo que é tomado como verdadeiro em uma época (FOUCAULT, 2000) e pelos quais também se colocam as bases que nos territorializam no mundo, condicionando nossas ações, podemos dizer que, em uma cena enunciativa, o direito de fala torna-se indiciário da hierarquia e das relações de poder entre os lugares discursivos que nela se constituem. 
Em grande parte dos perfis mencionados, temos aí um ponto importante de abordagem. Apesar de elemento primeiro que justifica a cena enunciativa, paradoxalmente, a velhice centenária ocupa um lugar destituído diante de outras instâncias enunciativas. Podemos dizer, assim, que é uma voz excluída.

Para Foucault, o mais evidente e familiar procedimento de exclusão é a interdição: não se tem o direito de dizer tudo, não se pode falar de tudo em qualquer circunstância e qualquer um não pode falar de qualquer coisa (FOUCAULT, 2000, p. 9). Em nosso caso, vemos um mecanismo aparentemente mais sutil, uma vez que a enunciação gira em torno dos sujeitos centenários, apontando para elementos que os singularizam. Podemos falar, então, de um processo que anula sua voz sob a máscara da inclusão. Isso porque, aparentemente ouvida, na maioria das vezes é uma palavra refutada por outras instâncias em termos daquilo que propõe.

Vemos aí a reposição de dois processos atuando de forma complementar: um processo de seleção e rejeição e, outro, pautado pelo princípio do comentário, que se posta, em nosso caso, em articulação ao anterior, como fala que interpreta e busca em fim dizer a verdade sobre aquilo do que comenta (FOUCAULT, 2000, p. 15).

A abordagem de Foucault sobre a fala do louco soa para nós extremamente próxima do que redunda nas matérias sobre as velhices centenárias estudadas nesse processo de exclusão. Segundo ele:

Desde a Idade Média, o louco é aquele cujo discurso não pode circular como o dos outros: pode ocorrer que sua fala seja considerada nula e não seja acolhida, não tendo verdade nem importância [...] pode ocorrer também, em contrapartida, que se lhe atribua, por oposição a todas as outras, estranhos poderes o de dizer uma verdade escondida, o de pronunciar o futuro, o de enxergar com toda ingenuidade aquilo que a sabedoria dos outros não pode perceber [...]. De qualquer modo excluída ou secretamente investida pela razão, no sentido restrito, ela não existia. (FOUCAULT, 2000, p. 11)

No entanto, mesmo quando passa a ser ouvida, a palavra do louco ainda continua a sofrer essa separação e rejeição. Tal processo passa a ser exercido 
de outro modo. De onde se conclui que a mera expressão de uma palavra não determina que esta não esteja segregada.

É o que ocorre com nossas velhices centenárias, cuja fala é separada como revelação sobre a longevidade que apenas pessoas tão idosas podem conhecer, mas, que, no entanto, na maioria das vezes, é uma palavra refutada ou cerceada, seja pelo teor daquilo que revela, seja pela fala de outras instâncias que a enquadram.

Desse modo, apesar de tais palavras serem aparentemente concedidas e visíveis no enunciado por meio de citações diretas e menções indiretas, de forma geral, elas somente entram no discurso como artifício de um ritual enunciativo cujo teor daquilo que proferem pouco importa. Nesses casos, além de haver a destituição do lugar de fala da personagem central, deslegitima-se a própria cena enunciativa pela construção narrativa contraditória e paradoxal.

Os terceiros que falam em nome das centenárias, por sua vez, também se constituem como sujeitos sem fala própria, na medida em que operam apenas como adjuvantes nessa cenografia cujo comentário, como lugar da palavra verdadeira, confere um determinado acento à enunciação que, no entanto, não diz respeito ao lugar de fala próprio que ocupam na relação com essas velhices centenárias. Repõe-se a exclusão, em mais um nível enunciativo.

Assim, as vozes visíveis nessa cena, de um lado, operam mais como alegoria do que são portadoras de seu próprio significado (KHOTE, 2000, p. 67) e, de outro, quando nos comentários atuam como agentes domesticadores, ratificadores de um discurso tanto normativo quanto disciplinar.

A mídia, dessa forma, apresenta uma enunciação restritiva diante de um universo muito mais amplo, que poderia ser explorado em torno desses sujeitos de trajetória única, cuja idade ainda poucos têm a possibilidade de alcançar. Um serviço manco, encoberto pelo mote da revelação de um segredo que não se desvela, em uma enunciação muda, inserida na gravidade de um cenário que pede maior visibilidade e amplitude de enfoques para que possa ser compreendido em suas demandas, considerando as necessidades de uma população que envelhece cada vez mais. 


\section{Referências}

A MULHER que chegou aos 112 anos a tomar um copo de whisky por dia. Delas, Lisboa, 17 set. 2018. Disponível em: http://bit.ly/2UgzJh6. Acesso em: 15 set. 2018 .

BANKS, A.; VP AMÉRICA LATINA; DIRETOR BRASIL. Brasil digital future in focus 2014. Press release. São Paulo: Comscore, 22 maio 2014. Disponível em: http:// bit.ly/2ZyZH3f. Acesso em: 25 abr. 2019.

BRASIL. Secretaria dos Direitos Humanos. Dados sobre o envelhecimento no Brasil. Brasília, DF, 2012.CAMARANO, A. A.; PASINATO, M. T. Introdução. In: CAMARANO, A. A. (org.). Os novos idosos brasileiros: muito além dos 60? Rio de Janeiro: Ipea, 2004. p. 1-22.

CHARAUDEAU, P. Discurso das mídias. São Paulo: Contexto, 2012.

COMO é a dieta da mulher mais velha do mundo, que acaba de completar 117 anos. BBC News, Rio de Janeiro, 30 nov. 2016. Disponível em: https://bbc. in/2KFUFPa. Acesso em: 15 abr. 2019.

DEBERT, G. G. A reinvenção da velhice: socialização e processos de reprivatização do envelhecimento. São Paulo: Edusp/Fapesp, 2012.

DELEUZE, G.; GUATTARI; F. Mil platôs: capitalismo e esquizofrenia. São Paulo: Editora 34, 2011a. v. 1.

DELEUZE, G.; GUATTARI; F. Mil platôs: capitalismo e esquizofrenia 2. São Paulo: Editora 34, 2011b. v. 2. 
FALEIROS, V. P. A política nacional do idoso em questão: passos e impasses na efetivação da cidadania. In: ALCÂNTARA, A. O.; CAMARANO, A. A.; GIACOMIN, K. C. (org.). Política nacional do idoso: velhas e novas questões. Rio de Janeiro: Ipea, 2016. p. 537-571.

FERRARI, M.; SODRÉ, M. Técnica de reportagem: notas sobre a narrativa jornalística. São Paulo: Summus, 1986.

FOUCAULT, M. A hermenêutica do sujeito. São Paulo: Martins Fontes, 2010.

FOUCAULT, M. A ordem do discurso. São Paulo: Loyola, 2000.

FREITAS, J.-M. M. Comunicação e psicanálise. São Paulo: Escuta, 1992.

GIACOMIN, K. C. Considerações finais. In: ALCÂNTARA, A. O.; CAMARANO, A. A; GIACOMIN, K. C. (org.). Política nacional do idoso: velhas e novas questões. Rio de Janeiro: Ipea, 2016. p. 593-615.

GIL, A. C. Métodos e técnicas de pesquisa social. São Paulo: Atlas, 2008.

GOLDENBERG, M. A bela velhice. Rio de Janeiro: Record, 2015.

GOMES, M. R. Palavra de ordem/dispositivo disciplinar. Galáxia, São Paulo, n. 5, p. 91-108, 2003.

GOMES, M. R. Jornalismo e ciências da linguagem. São Paulo: Hacker/Edusp, 2000.

ILC - CENTRO INTERNACIONAL DE LONGEVIDADE BRASIL. Envelhecimento ativo: um marco político em resposta à revolução da longevidade. Rio de Janeiro, 27 out. 2015. 
JENKINS, H. Cultura da convergência. São Paulo: Aleph, 2009.

KIRKPATRICK, D. O efeito Facebook: os bastidores da história da empresa que conecta o mundo. Rio de Janeiro: Intrínseca, 2011. Disponível em: http://bit. ly/2PbtZnS. Acesso em: 15 abr. 2019.

KOTHE, F. R. O herói. São Paulo: Ática, 2000.

LÉVI-STRAUSS, C. Introdução à obra de Marcel Mauss. In: MAUSS, M. Antropologia e sociologia. São Paulo: Edusp, 1974. v. 1.

LÉVY, P. Cibercultura. São Paulo: Editora 34, 1999.

LIESENBERG, C. Sob o signo do tempo: velhice e envelhecimento em perfis de idosos nas mídias. Tese (Doutorado) - Universidade de São Paulo, São Paulo, 2019.

LISBOA, V. IBGE: número de idosos com 80 anos ou mais deve crescer 27 vezes de 1980 a 2060. Agência Brasil, Rio de Janeiro, 26 out. 2016. Disponível em: http://bit.ly/2Iku1sZ. Acesso em: 25 abr. 2019.

MAINGUENEAU, D. Novas tendências em análise do discurso. Campinas: Pontes/ Unicamp, 1989.

MELO, J. M. et. al. Gêneros e formatos na comunicação massiva periodística: um estudo do jornal "Folha de S. Paulo" e da revista "Veja". In: Congresso Brasileiro de Ciências da Comunicação - INTERCOM, 21., 1998, São Paulo. Anais [...]. São Paulo: Universidade Metodista de São Paulo, 1998. p. 1-23. Disponível em: http:// bit.ly/2InjEES. Acesso em: 15 abr. 2019. 
MULHER completa 105 anos e revela o segredo para a longevidade. Correio da Manhã, Lisboa, 20 set. 2018. Disponível em: http://bit.ly/2ImIx3t. Acesso em: 15 abr. 2019.

ORLANDI, E. P. Análise de discurso: princípios e procedimentos. Campinas: Pontes, 2013.

PÊCHEUX, M. O discurso: estrutura ou acontecimento. Campinas: Pontes, 1997.

PIMENTEL, T. Mineira chega aos 107 misturando manga com leite e tomando um vinhozinho de vez em quando. G1, Belo Horizonte, 17 ago. 2018. Disponível em: https://glo.bo/2Zn0vbs. Acesso em: 15 abr. 2019.

RYAN, A. Mulher mais velha do mundo afirma que segredo da longevidade é ser solteira e comer ovos. Yahoo!, São Paulo, 4 nov. 2016. Vida e Estilo. Disponível em: http://bit.ly/2Ioizg4. Acesso em: 16 abr. 2019.

SAMORA, G. Cientista de 104 anos que pediu morte assistida vai tomar sedativo, cair no sono e morrer em 1 minuto. Uol, São Paulo, 7 maio 2018. Ciência e Saúde. Disponível em: http://bit.ly/2V3ZNAr. Acesso em: 15 abr. 2019.

SILVA, L. R. F. Da velhice à terceira idade: o percurso histórico das identidades atreladas ao processo de envelhecimento. História Ciência e Saúde, Rio de Janeiro, v. 15 , n. 1, p. 155-168, 2008. doi: 10.1590/S0104-59702008000100009

SIMÕES, C. C. S. Relações entre as alterações históricas na dinâmica demográfica brasileira e os impactos decorrentes do processo de envelhecimento da população. Rio de Janeiro: IBGE, Coordenação de Populações e Indicadores Sociais, 2016.

SOARES, R. Margens da comunicação: discurso e mídias. São Paulo: Annablume, 2009. 
SOUZA, T. A dona Ângela chegou aos 101 anos. Diário de Canoas, Canoas, 9 maio 2018. Disponível em: http://bit.ly/2UAg54y. Acesso em: 15 abr. 2019.

TERRIE, B. Ter amigos e não guardar rancor: os segredos de Leah para viver 106 anos. Uol, São Paulo, 8 jul. 2018. VivaBem. Disponível em: http://bit.ly/2Xjwebp. Acesso em: 16 abr. 2019.

TORRES, R. Kirk Douglas 100 anos: A vida e a carreira de um artista centenário. Adoro Cinema, Rio de Janeiro, 09 dez. 2016. Disponível em: http://bit.ly/2V49VZZ. Acesso em: 15 abr. 2019.

submetido em: 21 mar. 2019 | aprovado em: 22 abr. 2019 